vegetation and of the rocks followed. From the beginning, unusual looking plants attracted man's attention; and it was but a short step to cultivate flowers. With the advance of civilization, horticulture took a prominent place. In spite of the intensive exploration of the world for new plants during the last 1,500 years, not one unknown economic plant of any importance has been newly discovered. Even tung oil and soya bean, than which few plants have come into greater prominence recently, were cultivated several thousand years ago. On the other hand, many beautiful garden plants have been newly discovered.

Apart from horticulture, perhaps five hundred species of plants are now cultivated on a commercial scale-a very small proportion of the total known flora. The tendency is to reduce rather than increase the number, as the chemist learns how to synthesize plant products. Thus coal tar dyes supersede vegetable dyes, although coal tar is itself, ultimately, derived from vegetation ; and better varieties of wheat drive out inferior varieties. The increasing cultivation of herbs for the herb drug market perhaps restores the balance.

Apart from the staple cereal and fibre plants, and the various sources of such things as cellulose and timber, the most important economic crops to-day are : rubber, soya bean, quinine, tea, coffee, cocoa, sugar cane, banana, tung oil, varnish tree (Rhus), tobacco, opium, sisal and jute. The chief supply of nearly every one of these is now far from its original source, often in a different continent, as coffee, rubber, quinine and sisal. This has been brought about at the expense of the original vegetation, as a direct result of the growing economic interdependence of mankind. But it only became possible when the main features of the world's vegetation were known. It is obviously an advantage that all men who want tea or soap should be able to obtain these things, rather than that they should be confined to the few ; but mankind is going through a period of intense economic readjustment in order to achieve this desirable end of plenty of everything for all. There is a further conflict between what men need at any given level of civilization, and what 'interests' can persuade them to want.

The world is far from being botanically explored yet. But much of what remains to be done is predictable, thanks to increased knowledge. This enables us to carry on the work more systematically. There may not seem to be the same careless rapture in exploring a given region for largely predictable plants that there might be in wandering through unexplored worlds. But lack of knowledge is a real handicap. It is because we see the past world through eyes which have been opened that it looks romantic. To contemporary man the vegetation must have been confusing, exasperating and overwhelming. So far as plant exploration is concerned, the present is the age of the intensive specialized botanical explorer and the chemist.

\title{
PRESERVATION OF GEOLOGICAL RECORDS*
}

\section{By Dr. M. MACGREGOR, \\ Geological Survey of Great Britain}

$\mathrm{T}$ HE preservation in a carefully documented and permanent form of geological records of all kinds is a matter which should be regarded as of the utmost importance, and the opportunity is taken here of stressing the need for conjoint action to deal with it. If the examples used by way of illustration are drawn entirely from Scottish sources, it is partly because they have come directly under my own observation and partly because the suggestions advanced may gain in cogency if their application to one particular region is emphasized.

The importance of preserving geological sections of outstanding.or critical significance has long been récognized. These may be conveniently grouped into three broad, more or less arbitrary, categories.

- Substance of an address prepared for the Conference of Delegate of Corresponding Societies at the Dundee meeting of the British Association.
They may, for example, illustrate unique episodes in the history of the earth ; they may represent landmarks in the progress of geological thought or symbolize striking advances in our knowledge of geological processes ; they may, again, be sections that require re-examination and re-consideration from time to time in the light of modern research. For these and other reasons-historical, educational and scientific-the question of their preservation is a challenging one for all geologists.

These three categories may be very briefly dealt with. It would not be easy to select a more impressive illustration of the first of them than the little trial quarry at the roadside $3 \frac{1}{2}$ miles north-west of Inchnadamph, in Sutherlandshire (Geol. Surv. Photo. C. 2019). Here the basal beds of the Torridon Sandstone, containing windfacetted pebbles, rest discordantly upon an 
eroded and weathered surface of Lewisian Gneiss. Not only does this section allow us a glimpse of a land-surface that existed in early Torridonian times, more than 500 million years ago, but also it illustrates clearly and diagrammatically the structural relations of two of the most ancient rock-formations known. It would be a great loss if the section were to be swept away during the road-widening schemes that are in contemplation, and assurances have been obtained that it will not be destroyed. Another striking example that may be adduced is the well-known "Fossil Grove" at Victoria Park, Whiteinch, now a museum under the care of the Parks Department of Glasgow Corporation (Geol. Surv. Photos. C. 3560-61).

Of sections falling within the second category two instances may be given. The first of these is the historic exposure in the River Jed, near Jedburgh, discovered by Hutton in 1787 and described by him as providing unassailable evidence for elevation of the land, followed by erosion, subsidence and a fresh cycle of deposition. The originality of Hutton's genius is perhaps nowhere more fully exhibited than in his interpretation of the Jed River section. This exposure (Geol. Surv. Photo. C. 3494), which shows the nearly horizontal sandstones and marls of the Upper Old Red resting unconformably on highly folded Silurian rocks, was in danger of being overgrown and obscured, but now, owing to the generosity of Provost Veitch, it has been largely cleared of vegetation and debris and a pathway constructed to it. The second example which may be quoted under this heading is the striated rocksurface on the south face of Blackford Hill, Edinburgh, known as Agassiz' Rock (Geol. Surv. Photo. C. 2079). This also is of historic interest, since it was during a visit to the locality in the latter part of 1840 that Agassiz recognized the grooved surface as the work of glaciers. A number of years ago the Edinburgh Town Council, at the request of the Edinburgh Geological Society, agreed to protect the rock-face with a railing and to erect a commemorative tablet.

Within the third category may be fitly included various sections on the slopes of Arthur's Seat, Edinburgh, which have from time to time been re-interpreted in the light of increasing knowledge. Some of these, on Salisbury Craigs (Geol. Surv. Photos. B. 928-9), were at one time in danger of being quarried away, but the whole area of Arthur's Seat is now a national park under the custody of H.M. Office of Works.

Clearly, however, the preservation of important or critical sections is only practicable in a limited number of cases, and in this connexion brief reference may be made to the exposures of fossiliferous clays and sands which were laid bare about
1868-69 in Cowden (or Cowdon) Glen, Renfrewshire, during the construction of a railway line between Caldwell and Neilston. James Geikie, Croll, Bennie and other geologists who examined the excavations came to the conclusion that the fossiliferous beds, with their mammalian and other remains, were deposited between two distinct boulder clays and were accordingly interglacial in age. Craig, on the other hand, claimed: $(a)$ that much of the 'upper' boulder clay was due to landslips at the side of the valley bringing down portions of the 'lower' boulder clay over the laminated material; and $(b)$ that where it was definitely in situ above the latter it was of a gravelly nature (with lumps of the underlying sediments) and owed its formation not to the action of ice but to that of water. While the interglacial age of these beds is now generally accepted, Gregory and Currie in 1928, after a review of the available evidence as presented by earlier workers and a critical examination of the vertebrate remains, concluded that the deposits were "post-glacial and probably Neolithic in age". The question is certainly an important one in its bearing upon the Glacial and post-Glacial history of the region. It cannot be discussed here, but the Cowden Glen sections will serve as illustrations of ones which we would much like to re-examine in the light of later work.

Perhaps the most important aspect of the problem, however, concerns the preservation in a permanent form of geological records in general. Although much has been accomplished in this respect, it is certain that a systematic and coordinated effort to deal more fully with the problem is both essential and urgent. Much valuable geological information can be obtained from excavations made for various purposes connected with industrial and allied undertakings, from boring and mining developments, from tunnelling and quarrying operations, from roadway and sewage schemes, from factory and housing extensions, and from temporary exposures in constructional work of all kinds. The machinery for dealing with shafts and borings for minerals more than $100 \mathrm{ft}$. in depth is already in existence, but in regard to the other operations enumerated there is a wide field not covered by any co-ordinated activity.

Much of the information that might be derived from such sources is lost, or is available only in a form that is difficult, and indeed often impossible, to interpret. Engineers and foremen in charge of constructional work, surveyors, well-sinkers and the like have their own special tasks and their own aims in view, and they cannot be expected to provide records in the form and with the detail required by the geologist. It is surely the duty of 
the latter to see that the exact information he needs is carefully collected and made available for purposes of research. This is done in the case of borings for minerals, and it seems essential that it should be done systematically in regard to temporary sections of all kinds.

The importance of such investigations and of their repercussions not only on scientific but also on economic problems is not sufficiently realized, and the opportunities they offer for adding to our knowledge are too often neglected. Certainly they will often be of small importance individually, but collectively they may well amount to an impressive body of valuable geological data. Their significance in the preparation of detailed geological maps need not be stressed. Temporary excavations have contributed much to our knowledge of the geological succession and structure in different areas, notably, so far as Scotland is concerned, around Edinburgh and Glasgow. On the other hand, it would be easy to cite examples of temporary exposures which were not examined and about which little or no information is now available. The cumulative loss to geology must be very considerable, and it is in the hope of minimizing it that the problem is raised anew. In the past, the preservation of records has been left too much at the mercy of accident, and it would seem essential to establish, or try to establish, some definite system of efficient safeguards.

Thus there are two objects to keep steadily in view. The first of these is the preservation, wherever possible, of sections of outstanding or critical significance. In a number of cases this has been secured through the co-operation and assistance of public bodies, and geologists must feel deeply indebted to these for their action. Private assistance has, as already stated, come to our aid in the case of the Jed River unconformity, while acknowledgment should certainly be made of the generous action of Major-General J. W. Stewart, when in 1930 he conveyed to the ownership of the
Royal Society of Edinburgh the ground at Inchnadamph on which the Peach and Horne memorial stands (Geol. Surv. Photos. C. 3550-51). Where preservation of important sections is possible, however, appeals for co-operation and assistance will come more effectively from a committee representative of geological opinion throughout the country. One other thing must be said in this connexion. It will not be out of place to suggest that geologists themselves are not always entirely free from blame in this matter, and that some restraint might be put on indiscriminate collecting at specially important and limited exposures.

The second and, in my opinion, the more urgent claim on our attention, is the preservation of carefully annotated records of exposures that are likely to be destroyed or to disappear, and of sections that are temporarily opened for examination. Included among the latter are excavations of all kinds as well as borings for whatever purpose these may have been sunk. The information they yield, scientific and economic alike, ought to be made available in a permanent and accessible form. To ensure this will require the active co-operation of geological and natural history societies and of university geological departments throughout the country, each responsible for a particular region and each reporting annually to a central organizing committee, either of the British Association or of the Geological Society. Brief abstracts of the work done in the different regions should be published at intervals, and these abstracts ought unquestionably to indicate where the fuller details are available, whether published or preserved in manuscript form. What is required is a register of new information derived from temporary sections and some system of ensuring that the full records, including any diagrams and photographs, are permanently retained. There is nothing extreme in this suggestion, and it ought to be possible to institute an efficient system of precautions against avoidable loss.

\section{OBITUARIES}

Sir Thomas Heath, K.C.B., F.R.S., F.B.A. GIR THOMAS LITTLE HEATH, who died on $\checkmark$ March 16, was one of the most learned and industrious scholars of our time. He was born on October 5, 1861, the third son of Mr. Samuel Heath of Thornton Curtis in Lincolnshire. Sent to school at Clifton College, Heath went on with a foundation scholarship to Trinity College, Cambridge; and there, reading for double honours, he took a first in both parts of the Classical Tripos, and was twelfth Wrangler in $\mathbf{1 8 8 2}$. Those years in Trinity are pleasant to look back upon. Henry Jackson was at his best; Acton, Glaisher and Robertson Smith intensified the atmosphere of learning; William Wyse, H. H. Turner, Henry Head and Alfred North Whitehead were among the undergraduates; James Gow was writing his "History of Mathematics"-_a. "convenient compilation", as G. J. Allman called it, but good enough to start Heath on the work of his life. He won his Trinity fellowship in 1885, as his eldest brother, R. S. Heath, afterwards professor of mathematics in Birmingham, had done two years before ; and many 